\title{
Role of AgNORs in Thyroid Lesions on Fine Needle Aspiration Cytology (FNAC) Smears
}

\author{
Mohammed Abdul Rasheed ${ }^{1}$, Mohammed Amanullah*2, Syed Parween Alii ${ }^{3}$ and Fouqia Butool ${ }^{2}$ \\ ${ }^{1}$ Assistant Professor, Department of Clinical Pathology, Shadan Institute of Medical Sciences, Hyderabad, India
}

${ }^{2}$ Department of Biochemistry, College of Medicine, Saudi Arabia

${ }^{3}$ Department Medical Laboratory Science, Saudi Arabia

*Corresponding author: Mohammed Amanullah, Associate Professor, Department of Clinical Biochemistry, College of Medicine,

Saudi Arabia

\section{ARTICLE INFO \\ Received: 幽 January 21, 2019 \\ Published: 㓞 February 06, 2019}

Citation: Mohammed Abdul R, Mohammed A, Syed Parween A, Fouqia B. Role of Agnors in Thyroid Lesions on Fine Needle Aspiration Cytology (Fnac) Smears. Biomed J Sci \& Tech Res 14(1)-2019. BJSTR. MS.ID.002499.

Abbreviations: FNAC: Fine Needle Aspiration Cytology; AgNORs: Silver Stained Nucleolar Organizer Regions; FNS: Fine Needle Sampling; FNA: Fine Needle Aspiration; NORs: Nucleolar organizer regions; DNA: Deoxyribonucleic acid
ABSTRACT

A total no of 119 cases of thyroid lesions were subjected to FNAC and were analyzed. Most of the cases occurred in females 113 (94.96\%) and 6 cases were noticed in males (5.04\%). Maximum number of lesions was seen in age group 21 to 30 years(39 cases). Cytological diagnosis was given in 119 cases. Benign lesions constituted 108 cases where as malignant lesions were 11 . Nodular goiter was the commonest benign lesion and papillary carcinoma of thyroid was commonest malignant lesion. AgNOR scoring was given in 100 cases and in 19 cases AgNOR scoring was not given due to poor cellularity of smears. The number of benign lesions was 90 and malignant lesions were 10 . In the present study malignant thyroid lesions (papillary carcinoma)showed AgNOR scoring 3.15 $\pm 0.64(\mathrm{SD}) \&$ and benign thyroid lesion(lymphocytic thyroiditis) showed AgNOR scoring of $1.69 \pm 0.10(\mathrm{SD})$. Comparative study by other workers alsoshowed significant difference between benign and malignant lesions. There was no significant variation in AgNOR score among the various benign lesions; whereas there was a significantly higher AgNOR score in malignant lesions of thyroid.

Keywords: Thyroid Lesions; Fine Needle Aspiration Cytology (FNAC); Silver Stained Nucleolar Organizer Regions (AgNORs) Technique; Cytological Diagnosis; Nodular Goiter; Papillary Carcinoma; Lymphocytic Thyroiditis

\section{Introduction}

Benign thyroid nodules are common and seen in $5-10 \%$ of adults and thyroid malignancy is the most common malignancy of endocrine system. Papillary thyroid carcinoma and follicular thyroid carcinoma are often curable and prognosis is good if identified in early stage. Nodular thyroid diseases are indicated by the presence of single or multiple nodules within the thyroid gland. To avoid unnecessary surgery, a thyroid scan, ultrasonography, and fine needle aspiration cytology (FNAC) are used as diagnostic tools to differentiate malignant nodules from benign lesions Cusick et al. [1,2] FNAC technique involves the aspiration of cell samples through a needle attached to a syringe. Needle is introduced into the thyroid swelling and negative pressure is created by the syringe (caliber of the needle generally used is such cases will be G-23). But, in cases of vascular tumors like thyroid; this technique is complicated by aspiration of significant amounts of fresh blood, which compromises the cellular concentration, preservation and interpretation Kate et al. [3,4].

In an attempt to overcome this problem, an alternative method was developed in France, non- aspiration technique or fine needle sampling (FNS). This technique was introduced by Zajdela et al. [5] Followed by Zajdela's study, various authors attempted this new method of aspiration. Fine needle aspiration (FNA) and fine needle 
sampling (FNS) is safe and easy and cause little or no discomfort to the patient. Many studies of the accuracy of FNAC diagnosis of solitary nodule with cytohistological correlation have been reported $[6,7]$. FNAC carries negligible risk of contamination by tumor cells. There is no contraindication to FNA of thyroid. The routine use of FNAC in the assessment of thyroid nodulesh as reduced the number of patients subjected to thyroidectomy for benign lesions of thyroid Melcher et al. [8]. The use of FNAC as a screening method to select solitary cold nodule for surgery has been documented Hashemi et al. [6,7]. Repeated FNA sampling over a period of time can be done to reinforce a benign diagnosis and it reduces the false negative rates Dwatkanath et al. [9].

Various attempts have been made to improve the diagnostic accuracy of FNAC, including morphometric studies, DNA measurement, immunohistochemical, and enzymes techniques for thyroid cancer with varying degrees of success.34FNAC provides a rapid, safe and accurate diagnosis of the solitary thyroid nodule Mulazim et al. [7]. A cytological diagnosis of malignancy allows preoperative irradiation and palliative therapy Ravetto et al. [10]. FNAC is of value in metastatic disease, to identify meta static tumors in thyroid. The importance of thyroid FNAC in pregnancy and childhood is well established. Ultrasound has made localization and accurate sampling possible. Impalpable nodule less than $1 \mathrm{~cm}$ in diameter are commonly detected on ultra sound examination Derlin et al. $[11,12]$. Repeat FNA can be done in some thyroid lesions when diagnosis cannot be made in first aspiration Dwatkanath et. al. [9].

Nucleus is the control centre of cell containing the blue print from which all the components of cell are constructed. This blue print is stored in the form of Deoxyribonucleic acid (DNA) arranged in the form of chromosomes. Nuclei contain dense structures called nucleoli, which are the sites of the ribosomal RNA synthesis and ribosome assembly. The nucleolus plays an essential role in the control of cell proliferation and protein synthesis. Nucleolar organizer regions (NORs) Crocker et al. [1315] are loops of ribosomal DNA that are transcribed to ribosomal RNA by RNA polymerase and then translated by the ribosome's into proteins. NORs are located on each of the short arms on acrocentric chromosomes Ghosh et al. [16,17] NORs are segments of DNA closely associated with nucleolus consisting of non-histone proteins, which are argyrophilic, and can be located by staining with silver nitrate [18] NORs are denatured as black-brown spots, they are termed as AgNORs.

Silver staining technique for nucleolar organizer regions (NORs) has been successfully applied to a wide variety of neoplastic lesions on pathological material in order to distinguish benign from malignant lesions [19-21]. In the present study silver staining technique was applied to study AgNOR counts in the neoplastic and non-neoplastic lesions of thyroid. AgNORs were counted in 100 best stained nuclei of FNAC smears under oil immersion microscope (X 1000), and mean number of AgNOR per nucleus was calculated. AgNOR counts were compared in benign and malignant lesions of thyroid [22,23].

\section{Materials and Methods}

The present study was conducted in the Department of Pathology, Kamineni Institute of Medical Sciences Narketpally, Telangana, India. All the cases of thyroid swelling were referred from the Department of Surgery \& ENT of this institute from January-2018 to December-2018. FNA was done in 119 cases and 100 cases were studied for AgNOR count. AgNORs were counted in 100 best stained nuclei of FNA smears under oil immersion microscope (x 1000), and mean number of AgNOR per nucleus was calculated. AgNOR counts were compared in benign and malignant lesions of thyroid [24].

\section{FNAC Technique}

Patient was placed in supine position with a pillow under the shoulders, so that the neck was extended. The thyroidgl and was fixed between the investigating fingers and the trachea. Thecontour, surface and consistency of the gland were noted and the target area identified.

\section{Procedure}

All the aseptic precautions were observed. The thyroid land was immobilized with two fingers of the left hand, right hand was used to manipulate. A 23 gauge needle was inserted into target area to the desired depth. Needle was moved back and forth at varying angles to the line of entrance, in order to sample the lesion adequately. Due to the capillary action the material entered the needle [25]. Once the material was seen in the hub of the needle, the needle was removed and pressure applied at the site of puncture. This technique gave an excellent feel of consistency of the tissues and improved precision.

In case of absence of material in the hub of needle, a $20 \mathrm{ml}$ disposable syringe was attached to the needle and negative pressure was applied. When material or blood was noticed in the hub of the needle, the piston of syringe was released; so that the pressure equalizes. Immediately then syringe along with needle was removed. Pressure was applied to the puncture site. The aspirate was expressed onto the surface of clean glass slide. Then the second slide was pressed over the first and the material was gently and evenly spread without crushing. Slides were made from FNA material, one slide was air dried before fixing in 95\% methyl alcohol. Rest of the slides were wet fixed in 95\% methyl alcohol. One air dried slide was stained with silver nitrate stain and rest of the slides were stained with Hematoxylin \& Eosin (H\&E) stain 35 and cytomorphological features observed. H\&E Stained FNA/ FNS smears were studied for cytomorphological features and FNA report was given. Criteria for classifying thyroid lesions was based as per the criteria given by Svante et al. [26].

In the present study all the benign lesions with different diagnosis with respective AgNORs score were compared with the FNA diagnosis of malignant lesions, or follicular neoplasm with their respective AgNOR scores. AgNOR staining was done as described by Bancroft et al. [27] briefly working solution of silver nitrate was 
prepared freshly by dissolving five grams of Silver nitrate in $10 \mathrm{ml}$ of distilled water. (50\% solution) (solution-I). $2 \%$ cellulose was dissolved in $100 \mathrm{ml}$ distilled water and $1 \%$ formic acid was added (Solution -II). Two parts of solution one (I) was added to one part of solution two (II) and filtered twice using Whatman's filter paper.

\section{Staining Method}

The air-dried slides were stained with freshly prepared silver nitrate working solution for a period of 30 minutes. Incubator was used and temperature of 37 degrees centigrade was maintained till the staining was over. There after washed in distilled water. Silver nitrate stained slide showed nucleolar organizer regions (NORs) and they appeared as intra nuclear black/brown dots under oil immersion lens of microscope(x 1000). They are called AgNORs. AgNORs were counted in 100 best stained nuclei in each case and mean number of AgNOR was calculated per nucleus.

\section{Inclusion Criteria}

All thyroid swellings subjected to FNA were included in the study.

\section{Exclusion Criteria}

Patients who had undergone FNA and diagnosed any time before January 2018 and presented for repeat aspiration were excluded from study.

\section{Results}

In the present study AgNOR staining was used along with assessment of cytomorphological features in FNA of thyroid lesions, 119 cases were studied \& cytological diagnosis was given. Out of 119 cases stained with silvernitrate, 100 cases showed cellular foci for nucleolar organizer regions (NORs) (Figures 1-6) and AgNOR score is given in Table 1. In remaining 19 cases AgNOR score was not given due to poor cellularity of the smears. Maximum numbers of lesions were seen in the age group 21 to 30 years (39cases). Six (6) cases were noticed in males (5.04\%) and hundred and thirteen (113) cases in females (94.96\%) (Table 2). Benign lesions constituted $108(90.75 \%)$ cases where as malignant lesions were 11 (9.24\%). Nodular goiter was the commonest benign lesion (36.97\%) and papillary carcinoma of thyroid was the commonest malignant lesion (5.88\%) (Table 3). AgNOR score obtained in the present study was compared with the study conducted by other researchers and is presented in Table 4. AgNOR Score ranged from 1.66 to 1.80 for Benign lesions and from 3.07 to 3.15 for Malignant lesions.

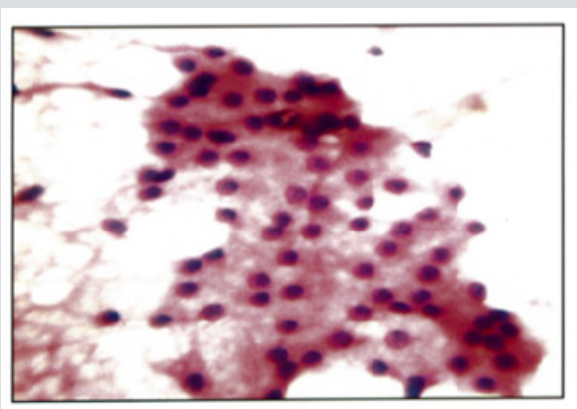

(a)

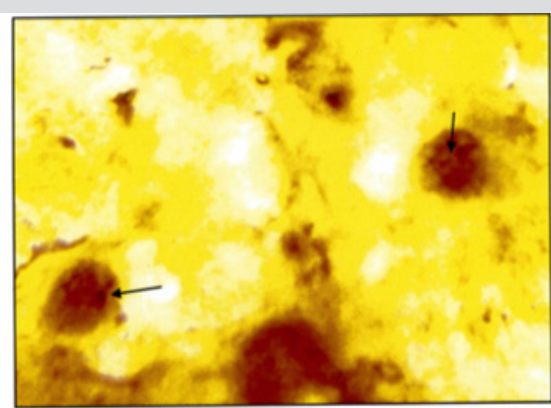

(b)

Note: Follicular Epithelial cells in mono layered sheets. Poorly cohesive.

Figure 1: a: Nodular goiter. (H \& E 400X).

b: Intra Nuclear brown/ black dots are seen in a case of nodular goitre (Arrow) (Silver Strain. 100x). AgNOR Score=1.74.

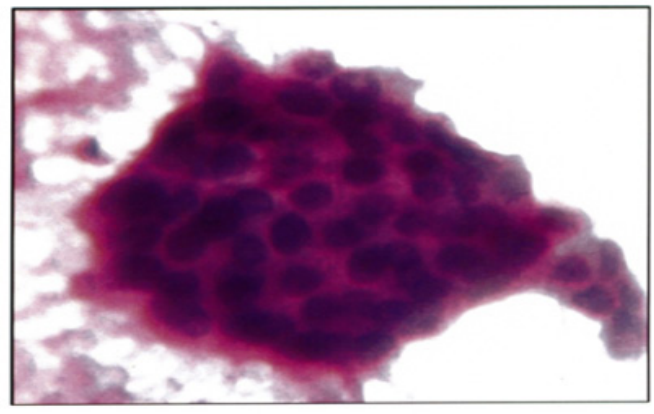

(a)

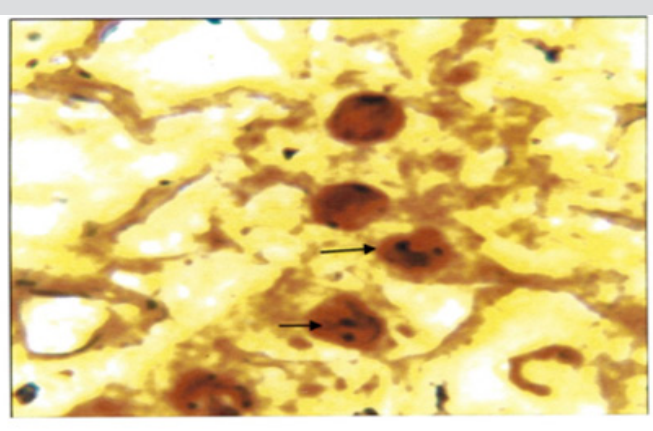

(b)

Note: Follicular Epithelial cells in monolayered sheets. Thick Colloid.

Figure 2: a: Colloid Goiter ( H\&E.400X).

b: Intra Nuclear brown/black dots are seen in a case of colloid goiter (Arrow) AgNOR Score: 1.71(X-1000). 


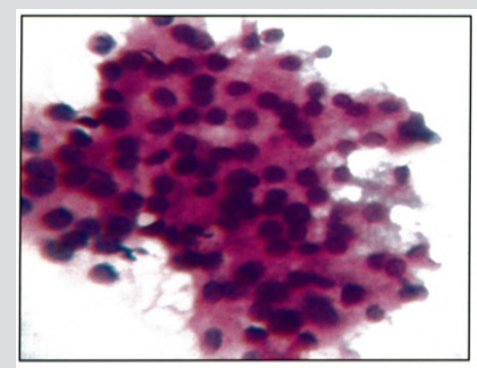

(a)

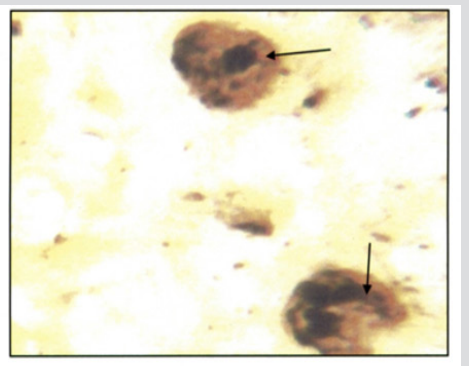

(b)

Figure 3: a: Hashimoto's thyroiditis (H\&E. 400X) Oxyphillic transformation of epithelial cells. Few lymphocytes.

b: Intra Nuclear brown/black dots are seen in a case of Hashimoto's thyroiditis (Arrow). AgNOR Score=1.80.(1000x).

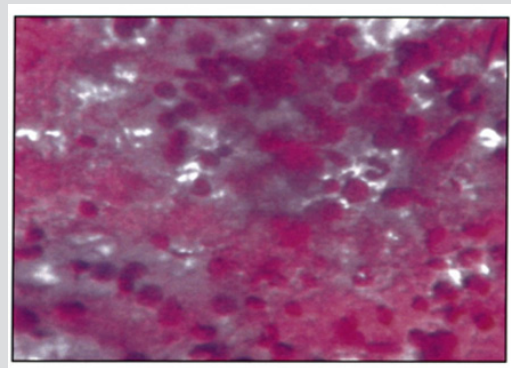

(a)

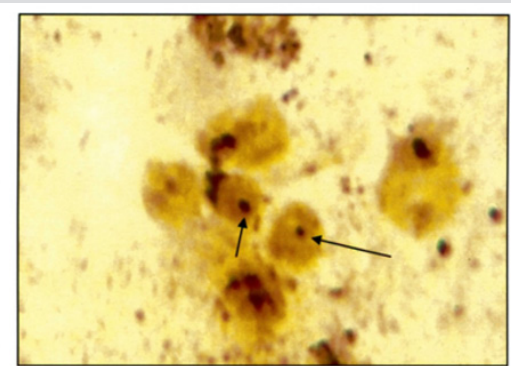

(b)

Figure 4: a: Lymphocytic throditis .(H\&E.400X) Lymphocytic infilterate.

b: Intra Nuclear brown/black dots are seen in a case of in a of lymphocytic thyroiditis. AgNOR Score=1.69(1000X).

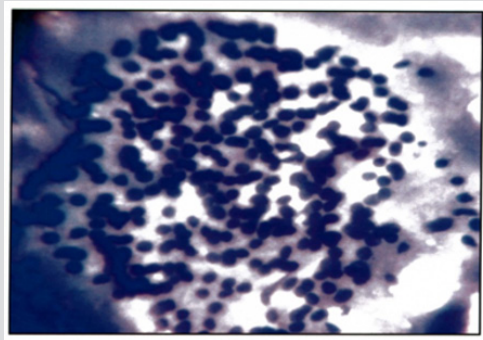

(a)

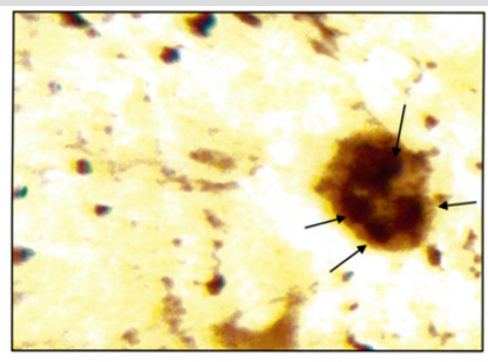

(b)

Note: Cellualar Smear. Nuclear crowding and overlapping.

Figure 5: a: Follicular neoplasm (Giemsa.400X).

b: Intra nuclear brown/black dots are seen in a case of in a of follicular neoplasm (Arrow). AgNOR Score=3.07(1000X).
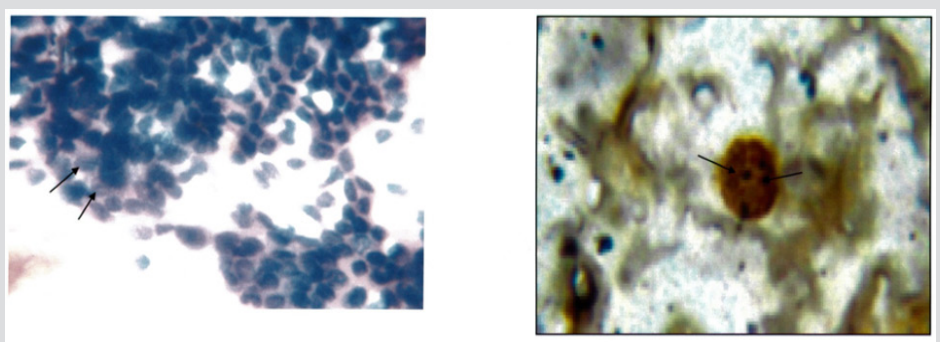

(b)

Note: Cellular Smear. Nuclear crowding and overlapping. Nuclear Grooves.(Arrow).

Figure 6: a: Papillary Carcinoma (H\&Ee.400X).

b: Intra nuclear brown/black dots are seen in a case of in a of Papillary Carcinoma (Arrow). AgNOR Score=3.15(1000X). 
Table 1: Malignant lesions showed higher AgNOR score in both the studies.

\begin{tabular}{|c|c|c|c|c|c|}
\hline \multicolumn{2}{|c|}{ Saritaasotra and Jaishree Sharma 30 (n=140) } & \multicolumn{3}{c|}{ Present Study (n=100 ) } \\
\hline FNA Diagnosis & No of cases(\%) & Mean AgNOR score/SO & No of cases (\%) & Mean AgNOR Score/SD & RANGE OF AgNOR score \\
\hline Colloid Goitre & $36(25.71 \%)$ & $2.94(0.85)$ & $9(9 \%)$ & $1.71(0.54)$ & $1.63-1.81$ \\
\hline Nodular goitre & $38(27.14 \%)$ & $2.82(0.08)$ & $36(36 \%)$ & $1.74(0.10)$ & $1.51-2.21$ \\
\hline Hashimoto's Thyroiditis & $17\{12.14 \%)$ & $2.76(0.08)$ & $18(18 \%)$ & $1.80(0.11)$ & $1.62-1.98$ \\
\hline Sub acute thyroiditis & $6(4.28 \%)$ & $2.61(0.68)$ & Nil & Nil & $1.53 \cdot 1.87$ \\
\hline Lymphocytic Thyroiditis & $3(2.14 \%)$ & $3.59(1.12)$ & $27(27 \%)$ & $3.69(0.10)$ & $3.01-3.13$ \\
\hline Follicular Neoplasm & $18(12.85 \%)$ & $3.15(0.80)$ & $3(3 \%)$ & Nil & Nil \\
\hline Hurthle Cell Neoplasm & $3(2.14 \%)$ & $3.38(0.96)$ & Nil & Nil & $3.06)$ \\
\hline Medullary carcinoma & $3(2.14 \%)$ & $3.47(0.94)$ & $7(7 \%)$ & $3.15(0.64)$ & $3.07-3.21$ \\
\hline Papillary Carcinoma & $16(11.42 \%)$ & $5.08(1.10)$ & 100 & & \\
\hline Total & 140 & & & & \\
\hline
\end{tabular}

Table 2: Age \& sex wise distribution of thyroid lesions (Cytological diagnosis) n=119.

\begin{tabular}{|c|c|c|c|}
\hline Age & No of cases (\%) & Sex/M (\%) & Sex/F (\%) \\
\hline 0-10 years & $1(0.84 \%)$ & Nil & $1(0.84 \%)$ \\
\hline $11-20$ years & $19(15.96 \%)$ & Nil & $19(15.96 \%)$ \\
\hline 21-30 years & $39(32.77 \%)$ & $2(1.68 \%)$ & $37(31.09 \%)$ \\
\hline $31-40$ years & $29(24.36 \%)$ & Nil & $29(24,36 \%)$ \\
\hline $41-50$ years & $16(13.44 \%)$ & $2(1.68 \%)$ & $14(11.76 \%)$ \\
\hline 51-60 years & $11(9,24 \%\}$ & Nil & $9(7.56 \%\}$ \\
\hline 61-70 years & $4(3.36 \%)$ & $6(5.04 \%)$ & $4(3.36 \%)$ \\
\hline Total & 119 & & $113(94.95 \%)$ \\
\hline
\end{tabular}

Note: Maximum No. of lesions were seen in age group 2lto30 years. (39 cases).

6 cases were noticed in males (5.04\%) \& 113 cases in females $(94.96 \%)$.

Table 3: Cytological diagnosis of thyroid lesions $(n=119)$.

\begin{tabular}{|c|c|}
\hline FNA Diagnosis & Number (\%) \\
\hline Colloid Goitre & $10(8.40 \%)$ \\
\hline Nodular goitre & $44(36.97 \%)$ \\
\hline Hashimoto's Thyroiditis & $22(18.48 \%)$ \\
\hline Lymphocytic Thyroiditis & $32(26.89 \%)$ \\
\hline Folicular neoplasm & $4(3.36 \%)$ \\
\hline Papillary Carcinoma & $7(5.88 \%)$ \\
\hline Total & 119 \\
\hline Total & 119 \\
\hline
\end{tabular}

Note: Benign lesions constitute 108(90.75\%) cases where asmalignant lesions were 11(9.24\%)

Nodular goitre was the commonest benign lesion(36.97\%)and papillary carcinoma ofthyroid(5.88\%) was commonestmalignant lesion.

Table 4: AgNOR score $(n=100)$.

\begin{tabular}{|c|c|c|}
\hline FNA Diagnosis & No of Cases (\%) & Mean AgNOR \\
\hline Colloid Goitre & $9(9 \%)$ & $1.71(0.54)$ \\
\hline Nodular goitre & $36(36 \%)$ & $1.74(0.10)$ \\
\hline Hashimoto's Thyroiditis & $18(18 \%\}$ & $1.80(0.11)$ \\
\hline Lymphocytic Thyroiditis & $27(27 \%)$ & $1.69(0.10)$ \\
\hline Follicular neoplasm & $3(3 \%)$ & $3.07(0.06)$ \\
\hline Papillary Carcinoma & $7(7 \%)$ & $3.15(0.64)$ \\
\hline Total & 100 & \\
\hline
\end{tabular}

Note: AgNOR Score ranged from 1.66 to 1.80 for benign lesions and from 3.07 to 3.15 for Malignant lesions. 


\section{Discussion}

Fine needle aspiration (FNA) and fine needle sampling (FNS) of thyroid are safe techniques that cause little or no discomfort to the patient and yield diagnostically significant information [18]. FNS is superior to FNA in vascular organs like thyroid $[28,29]$. FNS gives better perception of tumor consistency with control of hand. FNS gives better cell yield with little or no hemorrhage. The cytological architecture of thyroid was well preserved [30]. In the present study AgNOR staining was used along with assessment of cytomorphological features in FNA / FNS of thyroid smears to differentiate benign and malignant lesions of thyroid $[14,17]$. The amount of AgNOR staining reflects the proliferation of a given cell [31] .The number of AgNORs thus reflects nuclear and cellular activity. AgNOR staining technique is simple and can be done along with the FNA and report of AgNOR score and FNA can be given together. However there was overlapping of cells. Presence of limited single discrete cells caused counting in 100 cells quite tedious and time consuming Sarita Asotra et al. [32] studied 140 cases. There were 100 non-neoplastic and 40 neoplastic cases. Females formed the major group (84.28\%). Age ranged from 15 to 82 years.

Maximum number of cases were in the 20-40 years of age. Cytological diagnosis was given in all cases and AgNOR score was given. Higher AgNOR Score was recorded in malignant lesions compared to benign lesions (Table 4). Mehrotra et al. [21] studied cytomorphological features and the value of silver nitrate staining method in distinguishing non neoplastic, benign and malignant neoplasm in 140 cases. Lower AgNOR counts were recorded in cases of thyroiditis $(1.37 \pm 0.41)$ whereas the follicular carcinoma had higher AgNOR counts (5.04 \pm 0.52$)$. Higher AgNOR counts in malignant lesions were also recorded by Shechtman et al. [33]. In the present study higher AgNOR score was recorded in malignant lesions compared to benign lesions. Mean AgNOR score in lymphocytic thyroiditis was $1.69 \pm 0.10$ (S.D) and mean AgNOR count in papillary carcinoma was $3.15 \pm 0.64$ (S.D). The AgNOR score in a similar study by Sarita Asotra et al. [33] recorded higher score than in the present study for both benign and malignant lesions. However the distinction in the scores between the two groups remained comparable (Table 4). In the case of lymphocytic thyroiditis Sarita et al. [33] have studied 3 cases with a mean AgNOR score of 3.59 where as in the present study there were 27 cases with a mean AgNOR score of 1.69[34-36].

\section{Limitations of Study:}

In the present study there was lack of histopathological correlation and long term follow up of the cases, as the current study period was limited. Studying 2 or more smears for AgNOR scores would give better results than the single smear used in the present study $[37,38]$. As single smear staining with silver nitrate will be time consuming, staining slides in batches of 5 will save cost but would delay reporting.

\section{Conclusion}

AgNOR scoring on fine needle aspiration smears is a simple method. It can be combined with routine cytologic stains in the cytological evaluation, to differentiate benign from malignant lesions of thyroid.

\section{References}

1. Amritha Ghosh, Rajiv Kumar Misra (2000) Aspiration versus nonaspiration technique of cytodiagnosis-A critical evaluation in 160 cases. Indian J Pathol Micro biol 43(2): 107-112.

2. Bancroft JD, Marilyn Gamble (2001) Theory and practice of histological techniques ( $5^{\text {th }}$ edn,). Churchill Livingstone Edinburgh London 350-351.

3. Camargo RS, Shirata NK, Di Loreto C, Garcia EA, Castelo A, et al. (2006) Significance of AgNOR measurement in thyroidlesions. Anal Quant CytolHistol 28(4): 188-192.

4. Crocker J (1990) Nucleolar organizer regions: Underwood JCE, Currenttopics in pathology: Pathology of the nucleus. Berlin : Springer Verlag 91-149.

5. Cusick EL, Macintosh CA, Krukowski ZH, VM Williams, SW Ewen et al. (1990) Management of isolated thyroid swellings: a prospective six year study of fine needleaspiration cytology in diagnosis. Br Med J 301: 318321.

6. Derenzini M, Nardi F, Farabegoli F, Ottinetti A, Roncaroli F, et al. (1989) Distribution of silver stained interphase nucleolar organizer regionsas a parameter to distinguish neoplastic from non neoplastic reactivecells in human effusions. Acta Cyto 33(4): 491-98.

7. Derlin J, Hauch C, Chiehchao F, Weng H, Hung B (1997) Thyroid follicularneoplasm diagnosed by high resolution Ultrasonography with fine needleaspiration cytology. Acta Cytol 41: 487-491.

8. Desbpande V, Kapila K, Siva Sai K, Verma K (1997) Follicular neoplasm of the thyroid. Acta Cyto 43: 369-476.

9. Dube MK, Govil A (1995) Evaluation of significance of AgNOR counts in differentiating benign from malignant lesions in the breast. Indian Journal of Pathology \& Microbiology 3(1): 5-10.

10. Dwatkanath AA, Staren ED, D’ Amore MJ, Kluskens LF, Martirano M, et al. (1993) Importance of repeat fine needle biopsy in the management of thyroid nodules. Am J Surg 66(4): 350-352.

11. Eiothroo J, Franzen S (1962) Thin needle biopsy in the diagnosis of thyroid disease. Acta Radiol 58:3 2l-336.

12. Good Pastuer C, Bloom SB (1975) Visualization of NORs in mammalian chromosome using silver staining. J Chromo soma 53(1): 37-50.

13. Ghosh S, Bhattacharya S, Konar K, Ghosh TK, Majhi P (2009) Prognostic value of benign \& malignant lesion of larynx using AgNORs. Journal of the Indian Medical Association 107(10): 722-724.

14. Hashemi F, Nasserolestamic (1999) Comparison of argyrophilic nucleolar organizer regions in normal thyroid, nodular thyroid, nodular goiter andthyroid neoplasm. J Iran University Med. Science 6(3): 246252.

15. Hawkins F, Bellido D, Bernal C, Rigopoulou D, Ruiz Valdepeñas MP, et al. (1987) Fine needle aspiration biopsyin the diagnosis of thyroid cancer and thyroid disease. Cancer 59(6): 1206-1209.

16. Howell WM (1982) Selective staining of nucleolar organizer regions(NORs). In Busch $\mathrm{H}$, Rothblum L, eds. The cell nucleus. New York: Academic Press XI: 89-142.

17. Karmakar T, Dey P (1995) Role of AgNORs in diagnosis of thyroid neoplasm on fine needle aspiration smears. Diagncytopathol 12(2): 148-149.

18. Kate MS, Kamal MM (1998) Evaluation of fine needle capillary samplingin superficial and deep seated lesions, an analysis of 670 cases. Acta Cytol 42(3): 679-684. 
19. La Rosa GL, Belfoire A, Guiffrida D, Sicurella C, Ippolito O, et al. (1991) Evaluation of the fineneedle aspiration biopsy in the preoperative section of cold thyroidnodules. Cancer 67(8): 2137-2141.

20. Marley EF, Oertel YC (1997) Fine needle aspiration of thyroid lesions inpregnant and post-partum women. Diag Cytopathol 16(2): 122-125.

21. Mehrotra A, Aggarwal PK, Chandra T (1998) Cytopathology and AgNORs counts in fine needle aspiration cytology smears of thyroid lesion. Diag Cytopathol 19(4): 238-243.

22. Melcher NL (1997) To operate or not to operate? The value of fine needleaspiration cytology in the assessment of thyroid swelling. ClinPathol 50(11): 941-943.

23. Montironi R, Braseiseki A, Scerpelli M, Matera G, Albeste R (1991) Value of quantitative nucleolar features vis preoperative cytological diagnosis of follicular neoplasm of the thyroid. J Clin Pathol 44: 509-514.

24. Mulazim HB, Shahida N, Ghazala H, shahzad SQ, Mohammed M, et al. (2008) An updated audit of fine needle aspirationcytology procedure of solitary thyroid nodule. Diag Cytopatho 36(2): 104-112.

25. Nabriski D, Ness Abramof, R, Brosh TO, Konen O, Shapiro MS, et al (2003) Clinical relevance of nonpalpable thyroid nodules as assessed by ultrasound guided fineneedle aspiration biopsy. J Endrocrinol Invest 26(1): 3-4.

26. Ploton D, Menager M, AdnetJJ, Jeannesson P, Himber G, et al. (1986) Improvement in the staining and in the visualization of the argyrophilic proteins of the nucleolar organizer regions at the optical level. J Histochemistry 18(1): 5-14.

27. Ravetto C, Colombo L, Dottorini ME (2000) Usefulness of fine needle aspiration in the diagnosis of thyroid carcinoma. A retrospective study in 37,895 patients. Cancer cytopathol 90(6): 357-363.

28. Ruschoff J Prasser C, Cortez T, Hohne HM, Hohenberger W, Hofstadter F (1993) Diagnostic value of AgNORs staining in follicular cellneoplasm of

ISSN: 2574-1241

DOI: 10.26717.BJSTR.2019.14.002499

Mohammed Amanullah.Biomed J Sci \& Tech Res

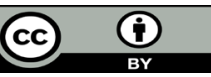

This work is licensed under Creative Commons Attribution 4.0 License

Submission Link: https://biomedres.us/submit-manuscript.php the thyroid: comparison of evaluation methods and nuclearfeatures. The American Journal of Surgical Pathology 17(12): 1281-1288.

29. Santos JEC, Gladwin Leimann (1988) Non-aspiration fine needle cytology Application of new technique to a nodular thyroid disease. Acta Cytol 32(3): 353-356.

30. Sarita Asotra, Jaishree Sharma (2008) Role of AgNORs in thyroid lesionson fine needle aspiration cytology smears. Journal of Cytology 25(1): 18-22.

31. Sharon Mair, Fiona Dunbar (1989) Fine needle cytology is aspirationsuction necessary? A study of hundred cases in various sites. Acta Cytol 33(6): 809-813.

32. Shechtman I, Koren R, Horowitz A, Halpern M, Gal R (1998) Diagnosticvalue of AgNOR staining in thyroid cytology. Anal Quant CytolHistol 20(3): 187-191.

33. Soderstorm N (1952) Puncture of goiters for aspiration biopsy. Apreliminary report. Acta Med Scand 144(3): 235-244.

34. Solymosi T, Toth HV, Sapi Z, Bodo M, Gal I, et al. (1996) Diagnosticvalue of AgNOR method in thyroid cytopathology: Correlation withmorphometric measurements. Diagnostic pathology 14(2): 140-144.

35. Stanley S Raphael (1976) Lynch's Medical laboratory technology ( $3^{\text {rd }}$ edn.), WB Saunders Company, Igakushoin Ltd Tokyo 924-925.

36. Svante R Orel, Gregory F Sterrett, Darrel Whitaker (2008) Fine Needle Aspiration Cytology ( $4^{\text {th }}$ Edition), Churchill Livingstone pp. 132-156.

37. Underwood JCE, Giri DD (1988) Nucleolar organizer regions as diagnostic determinants for malignancy. Journal of Pathol 155(2): 9598.

38. ZajdeJa A, Zillhardt P, Voillemot N (1987) Cytological diagnosis by fine needle sampling without aspiration. Cancer 59(6): 1201-1205.

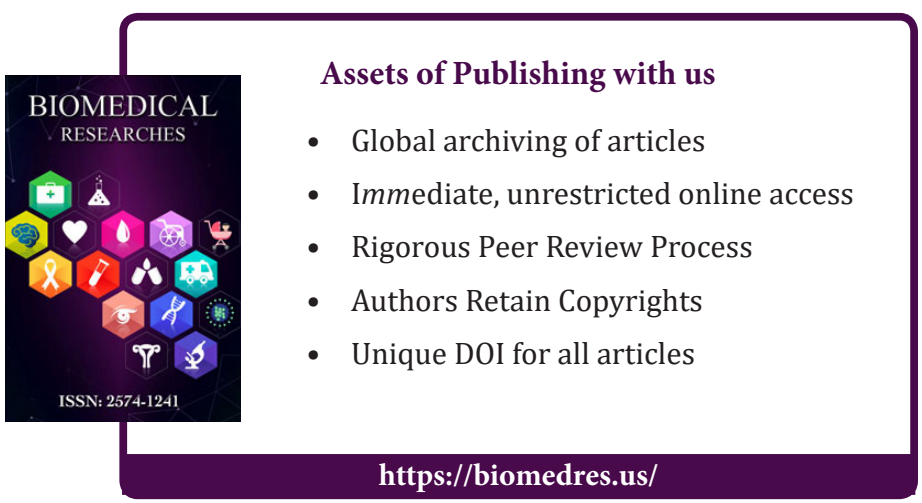

